\title{
A Three-Wave Validation of A Tool Measuring Teacher Identity
}

\author{
Bing Li \\ College of International Studies, Southwest University, Chongqing, China \\ daniel77@hku.hk
}

\begin{abstract}
Teacher identity has received recent attention, yet instruments assessing it lack in agreed constructs and repeated reliabilities. The present study thus accommodated the need for a comprehensive and replicable measure of teacher identity. A teacher identity inventory (TII) was constructed entailing three core components (teacher self-efficacy, organizational commitment, and job satisfaction). To validate it, three independent samples partook in three waves of study. Study 1 ( $N=236$ year-3 prospective teachers) generated a three-factor structure entailing seven scales through an exploratory analysis. Study 2 $(N=1,102$ year-4 prospective teachers) cross-validated the factor structure between a calibration sample $(N=539)$ and a validation sample $(N=563)$. A 34-item factor structure was finalized. Study $3(N=232$ beginning teachers) tested and verified the utility of the TII by examining how it was correlated with and regressed on the Job Demands-Resources Inventory (JD-RI). Limitations and implications for future research are discussed.
\end{abstract}

\section{Keywords}

teacher identity; the teacher identity inventory; validation

\section{Academic Discipline And Sub-Disciplines}

Educational psychology

\section{SUBJECT CLASSIFICATION}

Teacher education/development

TYPE (METHOD/APPROACH)

\author{
Validation (Methods)
}

\section{INTRODUCTION}

Over the last two decades, the issue of teacher identity has developed into a distinct area of research (Pillen, Beijaard, \& den Brok, 2013). Though fairly recent, a rich body of literature has sprung approaching varying aspects of teacher identity such as the conceptualization and characterization of its features (Akkerman \& Meijer, 2011; Day, Kington, Stobart, \& Sammons, 2006). Teacher identity merits attention justifiably. One primary reason is that teacher identity is held accountable for the overall landscape of education including, for example, curriculum reformations (Stenhouse, 1975), pupils' achievement (Day, Sammons, Stobart, Kington, \& Gu, 2007), and policy implementation (Robinson \& McMillan, 2006). Another reason is that attention invested in teacher identity can help teachers make sense of themselves as human beings (Zehm \& Kottler, 1993) and professionals (Day \& Gu, 2010).

Measuring teacher identity is in the meantime a longstanding issue (McNergney \& Satterstrom, 1984). Unfortunately, all due to the fact that the construct of teacher identify has been inconsistently conceptualized and measured from varying perspectives, a comprehensive picture of teacher has not yet been captured and agreed upon (Findlay, 2006). On the other hand, among the myriad of studies addressing teacher identity in the literature, attempts to quantify teacher identity are still lacking (Cheung, 2008). More importantly, of the handful of quantitative studies, no conceptualization of teacher identity has been held to in more than one study, nor has the instrument measuring teacher identity. This brings the research area of teacher identity into a predicament where researchers interested in quantifying teacher identity are either bewildered by and lost in the sheer variety of components chosen as representatives, or those researchers just quit the idea of depicting teacher identity in a quantifiable way.

Canrinus, Helms-Lorenz, Beijaard, Buitink, and Hofman (2012) postulated and verified a comprehensive model entailing four core components: job satisfaction, organizational commitment, teacher self-efficacy, and the level of motivation. The present study thus intended to validate an inventory to measure teacher identity through three of the abovementioned four core components, excluding the level of motivation; reasons of this exclusion are illustrated in the literature review that follows. We constructed a teacher identity inventory (TII) drawing on Canrinus and colleagues' (2012) framework with different pools of source inventories. To ensure the replicability and utility of this inventory as well as its validity and internal reliability, we recruited three independent samples in the present three-wave study. As pointed out in the previous research that prospective teachers and in-service teachers are different in magnitude of teacher identity (Day $\& \mathrm{Gu}, 2010)$, the present study included samples from both of the two teacher populations. Multiple methods of validation and analyses were employed to triangulate results from each of the three waves and independent samples. We concluded that a trustworthy measure of teacher identity is of necessity and importance where the TII devised and tested in the present study might provide a reliable and handy alternative. 


\section{TEACHER IDENTITY}

A cursory review of the literature suggests that attempts to conceptualize teacher identity largely follow three lenses: (1) an ontological lens; (2) a lens of professionalism; and (3) a lens of interactionism. The first lens focus on individual differences in teacher identity, arguing for teachers' inner traits (e.g., esteem and self-image) and selfconstruction of knowledge and values (e.g., Coldron \& Smith, 1999). The second lens favours the professional characteristics of the teacher identity, depicting teachers mainly as experts in subject matter, pedagogy, and didactics (e.g., Beijaard, Verloop, \& Vermunt, 2000). The third lens takes teacher identity as the joint function of personal (e.g., beliefs, values, and commitment) and contextual factors (e.g., school, family, and politics) (e.g., Day, 2011). As a result, the definition of teacher identity and the measure that follows are thrown into disputes. It is imperative that a unifying conceptualization be needed that puts together the strengths of the three lenses.

The present study conceived teacher identity as "different views that individuals have about themselves as teachers in general, and how [these views change] over time and in different contexts" (Dworet, 1996, p. 101). Simply put, this conceptualization provides a fuller account covering teachers' inner affiliation with teaching profession (selfsameness), differentiation from non-teachers (self-otherness), and fluctuating self-identification as a result of contextual and temporal changes.

\section{MEASURES OF TEACHER IDENTITY}

Because of controversies and disagreement arising from the three lenses noted earlier, measures drawing on them have been neither comprehensive nor agreed upon. Alternatively, different indicators such as teacher beliefs, cognitive knowledge, agency, and teacher roles have been examined in the name of teacher identity (Beijaard, 1995; Burn, 2007). It turns out that, however, these attempts are either inconsistent in the choice of core components, or liable to take only one or two components as the whole architecture of teacher identity.

As a consequence, some researchers focus on one core component only. For example, Beijaar, Verloop, and Vermunt (2000) assessed three indicators (subject matter experts, didactical experts, and pedagogical experts) of teacher identity. Yet put together, these three indicators tap the construct of teachers' knowledge only. Similarly, Cheung's (2008) study examined the construct of commitment to represent teacher identity in whole. Another consequence is that some researchers borrow components directly from psychosocial characteristics in general. Kremer and Hofman (1985), for example, adopted most items from a scale measuring Jewish ethnic identity regardless of teaching profession' particularities.

Despite variability in operationalization and measurement, there are still a handful of important components reiterated in empirical studies. Efficacy and commitment are the two most researched components. Research measuring teachers' efficacy includes but not limited to Flores and colleagues' (2010) study in Spain, Ezer, Gilat, and Sagee's (2010) study in Israel, and Hong's (2010) study in the U.S. Likewise, commitment has been evaluated in such research as Cheung's (2008) study in Hong Kong and Živković's (2013) study in Serbia. Other components that have garnered much attention include role conceptions (e.g., Beijaard, 1995), motivation (e.g., Flores et al., 2010), and job satisfaction (e.g., Živković, 2013). However, no single instrument in these studies has been replicated. Neither is there evidence for replicable reliability and validity. But good news is that, with heavy emphasis having been placed on certain constructs (e.g., efficacy and commitment), our scope of deciding on the core components could be narrowed and thus focused.

Canrinus and colleagues (2012) identified four most extensively researched constructs: teacher self-efficacy, organizational commitment, job satisfaction, and the level of motivation. These four core components, on the one hand, are all "under influence of both the person and the context in which the teachers work" (p. 116), thus to provid a fuller account of characteristics of teacher identity discussed earlier. On the other hand, a meta-analysis research on studies across 20 years demonstrates that these four components are of central importance to teacher identity (Day, 2002).

We need to note here, however, that Canrinus et al (2012) emphasized the change in level of motivation and measured it with a uni-item scale (i.e., "How motivated are you in teaching currently?"). In this case, we decided to exclude this component from our study, leaving three core components as follows.

Teacher self-efficacy. Friedman and Kass (2002) conceptualize teacher self-efficacy in two contexts: classroom and school. As such, teachers perceive their agency in terms of educating students (classroom self-efficacy) and making decisions in their organizations (school self-efficacy). An early study (Goodlad, 1984) reported that teachers who dropped out of teaching profession were low in self-efficacy. Another study (Allinder, 1994) documented that teachers with a stronger self-efficacy showed higher levels of organization engagement than their counterparts with lower self-efficacy. Recently, a large-scale study (Klassen et al., 2012) among 1,187 prospective teachers showed that teacher self-efficacy significantly mediated the relationship of workload stress to commitment in Canada, Hong Kong, and Thailand.

Organizational commitment. Organizational commitment is defined as teachers' affinity with their organizations (Meyer, Allen, \& Smith, 1993). This affinity implies their willingness to retain or leave. It is further broken down into three components (Meyer \& Allen, 1991). One is normative commitment referring to the sense of accountability and obligation to teaching, and the other is affective commitment delineating teachers' emotional attachment and involvement in teaching. The third one is continuance commitment that concerns a weighing of the cost paid and the benefit lost if leaving teaching profession. Surveying 178 high school teachers in California, Conley and You (2009) found that teachers' organizational commitment significantly mediated the relationship between role stressors (e.g., role overload and role conflict) and intentions to leave. Thomason and La Paro's (2013) study, among 740 teachers, confirmed teacher commitment as a significant predictor of the quality of teacher-student interactions. Mclnerney and colleagues (2014) considered data of 859 
primary and secondary schools teachers in Hong Kong. Results of their study indicated that all three types of organizational commitment were significantly, positively or negatively, correlated with teachers' psychological well-being.

Job satisfaction. Job satisfaction describes the extent to which people are satisfied with their job, psychologically or physiologically (Hoppock, 1935). As indicated in many studies, the degree of job satisfaction determines the attrition rate, collegiality, motivation, commitment to teaching, and overall job performance at the school level (George \& Sabapathy, 2011; Yucel \& Bektas, 2012). For example, through an extensive review, Van Dick (2004) concluded that teachers' job satisfaction was closely related to their physical and psychological well-being. Similar findings were echoed in Zembylas and Papanastasiou's (2005) study among 449 high school teachers in Cyprus where job satisfaction was found to be important in the construction of teacher empowerment. Brien, Hass, and Savoie's (2012) recent study collected data from 292 teachers and indicated that teachers' job satisfaction predicted their task performance.

\section{THE PRESENT STUDY}

The primary goals of the present study were to develop, calibrate, and validate a measure of teacher identity within the abovementioned three-indicator framework. This measure was expected to (1) tap the broad range of teacher identity through examining three core components (teacher self-efficacy, organizational commitment, and job satisfaction), and (2) exhibit good internal consistency of the measure across multiple populations. To these ends, the present study was collapsed into three waves (Study 1/2/3) among three independent samples (Year-3 prospective teachers, Year-4 prospective teachers, and beginning teachers, respectively) in a consecutive manner.

\section{STUDY 1: DEVELOPMENT OF THE TII PARTICIPANTS}

Sample 1 comprised 236 (male $=45$; female=191) year-3 prospective teachers, aged $21.57 \pm .51$, enrolled in a teacher training program at a normal university in mainland China. All these participants have completed their 1 -year-long teaching practicum insofar as to get hands-on teaching experiences.

\section{MEASURES AND DATA ANALYSIS}

The major goal of Study 1 was to develop a new inventory. Thus a 43-item Teacher Identity Inventory (TII) comprising three scales was schemed modelled on Canrinus et al.'s (2012) framework. Participants were required to self-report their agreement with statements indicated by a seven-point Likert scale ( $1=$ "not at all well"; $7=$ "extremely well"). Details of scales and items selection are as follows.

The scale for teacher self-efficacy. This 24-item scale includes two dimensions ("teacher self-efficacy in school context" and "teacher self-efficacy in classroom context") with 12 items for each. Items were selected from Friedman and Kass's (2002) Classroom and School Context (CSC) teacher self-efficacy scale. Previous studies using this scale have examined teacher self-efficacy in relation to such issues as job stress, burnout, and teacher identity (Canrinus et al., 2012; Helms-Lorenz, Slof, Vermue, \& Canrinus, 2011). Good psychometric properties of this scale have been reported. HelmsLorenz, Slof, Vermue, and Canrinus's (2011) study, for example, exhibited internal consistency through .77 (school context teacher self-efficacy) to .90 (classroom context teacher self-efficacy). A sample item is "I think I know how to improvise in response to changing circumstances when I teach".

The scale for organizational commitment. We assessed organizational commitment using a revised 15-item version of Meyer, Allen, and Smith's (1993) scale. Each of the three components (affective commitment, continuance commitment, and normative commitment) was measured via five items. As suggested in the literature, this scale is more often used in business and medical settings (e.g., Lin \& Hwang, 2014). To adapt it for the teaching context, we replaced terms like "nursing" and "counselling" with "teaching" in all items. This scale has been validated across cultures and professions, with internal consistency ranging from .77 to .85. A sample item is "I feel lucky to have entered the teaching profession".

The scale for job satisfaction. Job satisfaction is assessed by 4 items denoting "salary and fringe benefits". These four items were borrowed from the Minnesota Satisfaction Questionnaire-Short Form (MSQ-SF) (Weiss, Dawis, England, \& Lofquist, 1967) and the Job Satisfaction Index (JSI) (Giacometti, 2005). We trimmed off items overlapping the other three indicators, for example, "motivation to teach" and "emotional factors" from the JSI, and "intrinsic satisfaction" from the MSQ. A reliability coefficient of .57 was reported in Giacomett's (2005) study. Certainly, this scale needs further validation in the present study. One sample item is "My salary adequately meets my needs".

To field the TII in the Chinese context, the process of translations and back translation was executed (Harkness \& Schoua-Glusberg, 1998). All the source scales were firstly translated into Chinese, and then back translated into English by two PhD degree holders who had majored in English for B.A. and M.A. degrees and were then working on educational psychology. Through comparisons, the source scales were translated to Chinese again. Face validity of the TII was evaluated by a panel (a lead developer of the TII, an expert/professor in educational psychology, two PhD degree holders in educational psychology, and five prospective teachers from the target population) on item clarity, content, relevance, and acculturation (Secolsky, 1987).

Because the scales in the TII have not been used together in prior research, an exploratory factory analysis (EFA) was used. With missing values a priori replaced by series means, we executed the principal component analysis (PCA) to reduce dimensions via varimax rotation (Nunnally \& Bernstern, 1994). Factor loadings with absolute values lower than .40 were suppressed because the sample size was not very big (Field, 2000). 


\section{RESULTS}

Eight factors were engendered explaining $66.93 \%$ of variance. Factor 1 contained three items from the scale of job satisfaction. Factors 2, 3 and 4 subsumed all but one items denoting the three dimensions of organizational commitment. The scale of teacher self-efficacy, however, was split into three factors $(5,6$, and 7$)$ rather than two. Factor 8 was made up of two cross-loaded items from the scale of teacher self-efficacy in classroom context.

We examined Factors 6 and 7 carefully, and found out that these two factors pertained to the scale of teacher self-efficacy in school context. Interestingly, Factor 6 stressed teachers' perceived self-efficacy in decision making of school affairs, containing items like "I am actively involved in important decision-making processes at school", while Factor 7 emphasized teachers' perceived self-efficacy in dealing with relationships in school context with items like "When I have problems at school, I know whom to turn to". A particular note should be made that Friedman and Kass (2002) asserted that, in understanding teacher self-efficacy, leadership self-efficacy and relationship self-efficacy were of importance in that "the teacher operates simultaneously as a leader and as an employee" (p. 677) and "one social system connect the teacher to the students; the other connects the teacher to colleagues and the principal" (p. 678) (see also Bangs \& Frost, 2012). Therefore we decided to further divide teacher self-efficacy in school context into two subscales: leadership teacher self-efficacy and relationship teacher self-efficacy.

We then executed item analysis to evaluate item-total correlations. A cut-off of less than .30 and above .70 was observed for item removal (Ferketich, 1991). Three items (item-total correlations were .27, .19, and .25, respectively) measuring organizational commitment were deleted. Another two items that clustered in Factor 8 were also eliminated for heavy cross loadings (item 30 with factor loadings of .65 and .50; item 31 with factor loading of .58 and .42). As a result, 38 items remained.

Internal consistency was examined via Cronbach's alpha (CA). The results in Table 1 indicated that the TII was internally reliable with coefficients ranging from .70 (job satisfaction) to .92 (affective commitment).

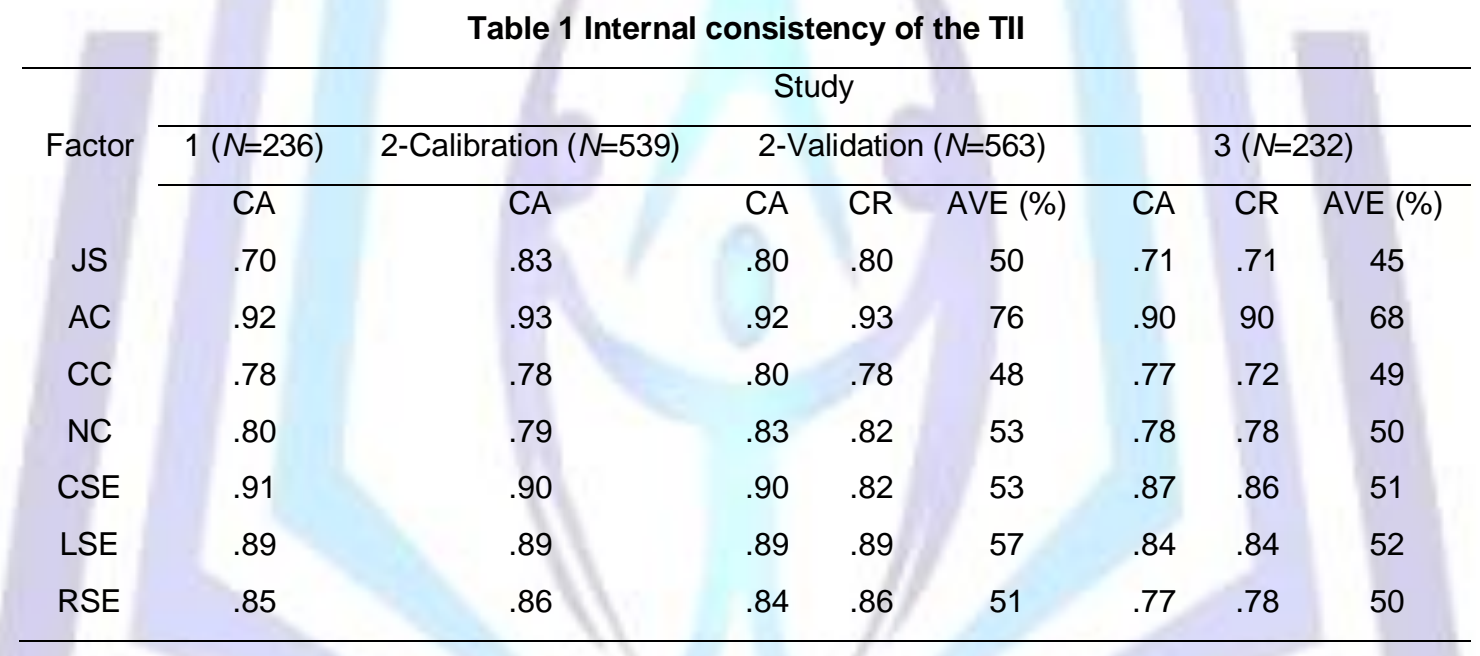

Note: $\mathrm{CA}=$ Cronbach's alpha; $\mathrm{CR}=$ composite reliability; $\mathrm{AVE}=$ average variance extracted; JS=job satisfaction;

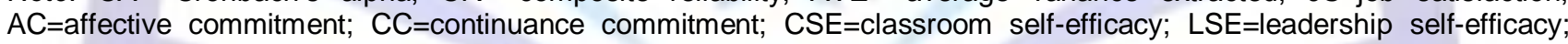
$\mathrm{RSE}=$ relationship self-efficacy.

\section{STUDY 2: CROSS-VALIDATION OF THE TII}

\section{PARTICIPANTS}

Sample 2 was 1,102 (male=366; female=736) year-4 prospective teachers, aged $22.74 \pm .65$ years, from a normal university in mainland China. All these participants held teaching certificates conferred by the Ministry of Education, China. They were convenience sampled through class units (26 classes in total).

\section{Measures and data analysis}

Study 2 was primarily for the purpose of cross-validation. Therefore Sample 2 was randomly split into two halves. One subsample was used as a calibration sample for a further EFA, consisting of 539 participants (male=182; female=357). The other subsample was a validation sample with 563 participants (male=184; female=379) for a confirmatory factor analysis (CFA). The CFA was performed grounded in the factor structure yielded with the calibration sample, so no alternative competing within-sample models were tested (Browne, 2000).

The Teacher Identity Inventory (TII). The resulting 38-item TII was employed in Study 2. Three scales and seven dimensions were assessed through a seven-point Likert type measurement: (1) the scale for job satisfaction (four items); (2) the scale for organizational commitment (12 items); and (3) the scale for teacher self-efficacy (22 items; ten items for classroom self-efficacy, six items for leadership self-efficacy, and another six items for relationship self-efficacy). 
Face validity of the TII was checked following two steps. First, in the end of the data collection in Study 1, opinions on wording and intelligibility of items were invited from 20 participants. Second, the TII with reworded items were evaluated by the same panel as in Study 1.

\section{RESULTS}

With the calibration sample, seven factors were yielded as expected by the PCA via varimax rotation. Variance explained accumulated to $66.25 \%$. All the items loaded neatly on the factors they were theoretically supposed to be. There was only one item that cross-loaded significantly on relationship self-efficacy and leadership self-efficacy. Four items were found to load weakly (loadings <. 40) on the factor for classroom self-efficacy, which were thus removed (Raubenheimer, 2004). As a result, a total of 34 items were retained.

The results of analysis on internal structure of the resultant 34 items are shown in Table 1. Internal consistency of the seven factors was good, ranging between .78 (continuance commitment) and .93 (affective commitment).

With the validation sample, the CFA was performed via AMOS 21 on the generated seven-factor model. Results are shown in Table 3. Judging by the benchmarks for indices (Bryrne, 2010), the $x^{2} / \mathrm{df}(2.27)$ demonstrated that the hypothesized model was robust even when the sample size was large $(N=563)$. The CFI (.94) indicated that the hypothesized model adequately described the sample data. The values of GFI (.91) and NFI (.90) suggested that the model fit were marginally adequate. What is more, the SRMR (.05) told us that the average value of all standardized residuals derived from a well-fitting model, and the RMSEA (.05) also indicated good fit.

Table 3 Confirmatory factor analysis of the TII in Study 2 and Study 3

\begin{tabular}{lcccccccc}
\hline \multicolumn{1}{c}{ Study } & $\mathrm{X}^{2}$ & $\mathrm{df}$ & $\mathrm{X}^{2} / \mathrm{df}$ & $\mathrm{CFI}$ & $\mathrm{GFI}$ & $\mathrm{NFI}$ & SRMR & RMSEA \\
\hline 2-Validation $(N=563)$ & 1107.33 & 487 & 2.27 & .94 & .91 & .90 & .05 & .05 \\
$3(N=232)$ & 801.70 & 497 & 1.61 & .91 & .90 & .90 & .05 & .06 \\
\hline
\end{tabular}

Note: $\mathrm{x}^{2}=$ Chi-square; $\mathrm{df}=$ degrees of freedom; $\mathrm{x}^{2} / \mathrm{df}=$ Chi-square/degrees of freedom; CFI = Comparative Fit Index; GFI $=$ Goodness-of-Fit Index; NFI = Normed Fit Index; RMSEA = root mean square error of approximation; SRMR = standardized root mean square residual.

In testing the reliability of the hypothesize model, the composite reliability $(\mathrm{CR})$ and average variance extracted (AVE) were calculated in addition to CA. As exhibited in Table 1, the CR of each factor was equal to or greater than .80, while the AVE by all factors but one exceeded $50 \%$, indicating fairly acceptable convergent validity (Fornell \& Larcker, 1981). CAs were no smaller than .80, similar in magnitude to the results yielded from the calibration sample. We therefore concluded that the seven factors of the TII were conceptualized appropriately relating to and testing the same constructs consistently.

\section{STUDY 3: FURTHER VALIDATION OF THE TII}

\section{PARTICIPANTS}

Sample 3 were 232 ( $m a l e=28$; female=204) beginning teachers, aged $23.68 \pm 1.32$, from 183 different schools. They had averagely two years of teaching experience. Among them, 132 (57\%) were teaching in secondary high schools, 75 (32\%) were from junior high schools, and $25(11 \%)$ were elementary school teachers.

\section{MEASURES AND DATA ANALYSIS}

In Study 3, the construct validity of the TII was further assessed via CFA. Moreover, we tested the utility of the TII by examining how it was correlated with and regressed on an established inventory for perceived work environment.

The Teacher Identity Inventory (TII). Through calibration and validation in Study 2, the TII retained 34 items making up seven factors.

The Job Demands-Resources Inventory (JD-RI). The JD-RI (Demerouti, Bakker, Nachreiner, \& Schaufeli, 2001) is a 28-item inventory, consisting of seven dimensions: two for job demands (quantitative demands and emotional demands) and five for job resources (superordinate support, workmate support, performance feedback, job autonomy, and growth opportunities). This inventory has been widely used in examining such work-related issues as work performance, professional identity, and psychosocial well-being (e.g., Bakker, ten Brummelhuis, Prins, \& der Heijden, 2011). Theoretically and empirically, employees in stressful work environment characterized by high quantitative and emotional demands are supposed to score low in organizational identification, in opposition to those in resourceful work environment where the five abovementioned job resources are more available (e.g., Lorente Prieto, Salanova Soria, Martínez Martínez, \& Schaufeli, 2008).

Therefore, we hypothesized that the scales of the TII, at least partially, would be negatively correlated with and regressed on job demands of the JD-RI. In contrast, job resources would be, at least in part, positively correlated with and predictive of scales of the TII. 


\section{RESULTS}

The results of fitting the dataset of Sample 3 to the model are summarized in Table 2. All indices but RMSEA demonstrated good model fit (Bryrne, 2010), with CFI, GFI, and NFI marginally meeting the threshold of .90 and SRMR reaching .05 , while $x^{2} / d f$ was far lower than 3 . However, the value of RMSEA (.06) still represented acceptable fit in terms of reasonable errors of approximation in the population (Browne \& Cudeck, 1993).

The alpha estimates of internal consistency for the TII in Study 3 are presented in Table 2. Compared to the results in Study 2, AVE of all factors dropped negligibly with two factors (job satisfaction and continuance commitment) lower than the recommended value of 50\% (Hair, Black, Babin, \& Anderson, 2010). However, the CR and the CA for each factor were greater than .70, with the highest reaching .90 . We still could conclude that the convergent validity of the construct was adequate and thus the seven factors were appropriate conceptualizations.

The correlation coefficients among the scales of the TII and the JD-RI are shown in Table 3. The results largely supported our hypotheses. First, quantitative demands and emotional demands were negatively correlated with all scales of the TII but continuance commitment. Second, all the five scales for job resources were mostly positively and significantly correlated with the scales of the TII, with the exception of continuance commitment, too.

Table 3 Zero-order correlation coefficients: the TII and the JD-RI $(N=232)$

\begin{tabular}{|c|c|c|c|c|c|c|c|}
\hline & JS & $A C$ & $\mathrm{CC}$ & $\mathrm{NC}$ & CSE & LSE & RSE \\
\hline Quantitative demands & -.06 & -.12 & .12 & -.08 & -.04 & -.14 & -.05 \\
\hline Emotional demands & -.20 & $-.24 n$ & $.17^{n}$ & -.06 & -.10 & $-.19^{n}$ & -.11 \\
\hline Superordinate support & $.34^{* \pi}$ & $.39^{\pi \pi}$ & -.01 & $.19^{\pi x}$ & $.27^{\pi \pi}$ & $.44^{\pi \pi}$ & $.51^{\pi \pi}$ \\
\hline Workmate support & $.26^{\pi \pi}$ & $.33^{* \pi}$ & .03 & $.17^{\pi \times}$ & $.22^{\pi x}$ & $.25^{* \pi}$ & $.41^{\pi \pi}$ \\
\hline Performance feedback & $.31^{\prime \prime}$ & $.31^{\prime \prime}$ & -.02 & $.19^{\prime \prime}$ & $.28^{\prime \prime}$ & $.32^{\wedge}$ & $.344^{\circ}$ \\
\hline Job autonomy & $.26^{\pi *}$ & $.32^{\pi *}$ & -.06 & $.15^{*}$ & $.24^{\pi *}$ & $.19^{\pi \times}$ & $.24^{\pi \times}$ \\
\hline Growth opportunities & $.34 "$ & $.58^{\wedge}$ & $.15^{\circ}$ & $.31^{n}$ & $.19^{\prime \prime}$ & $.19^{\prime \prime}$ & $.32^{n}$ \\
\hline
\end{tabular}

Note: * $p<.05 ;{ }^{* *} p<.01 ; \mathrm{JS}=$ job satisfaction; $\mathrm{AC}=$ affective commitment; $\mathrm{CC}=$ continuance commitment; CSE=classroom self-efficacy; LSE=leadership self-efficacy; RSE=relationship self-efficacy.

Hierarchical multiple regressions were then conducted, with all the seven factors of the TII entered as the dependent variables, controlling for gender. Table 4 summarizes these regression analysis results. Overall, the TII could be predicted by the total score of the JD-RI after controlling for possible confounds. Specifically, three factors of teacher identity (job satisfaction, affective commitment, and leadership self-efficacy) were negatively and significantly predicted by job demands, emotional demands in particular. Also as expected, all the seven factors of teacher identity were found to be positively and significantly predicted by four job resources (performance feedback, growth opportunities, superordinate support, and workmate support). Among others, growth opportunities and performance feedback were the two strongest predictors.

Table 4 Predicting teacher identity from perceived work environment

\begin{tabular}{llllllll}
\hline Teacher identity & JS & AC & CC & NC & CSE & LSE & RSE \\
\hline Adjusted $R_{\text {gender }}^{2}$ & -.003 & -.004 & -.004 & -.004 & -.003 & .042 & .017 \\
Adjusted $R^{\star}$ JD-R & .193 & .411 & .034 & .086 & .101 & .251 & .316 \\
$\beta_{\text {Job demands }}$ & ${ }^{*} .16_{\mathrm{ED}}$ & ${ }^{* *}-.18_{\mathrm{ED}}$ & - & - & - & ${ }^{*} .12_{\mathrm{QD}}$ & - \\
$\beta_{\text {Job resources }}$ & ${ }^{*} .15_{\mathrm{PF}}$ & ${ }^{* * *} .49_{\mathrm{GO}}$ & ${ }^{* *} .20_{\mathrm{GO}}$ & ${ }^{* * *} .26_{\mathrm{GO}}$ & ${ }^{*} .18 \mathrm{PF}$ & ${ }^{* * *} .33_{\mathrm{SS}}$ & ${ }^{* *} .34_{\mathrm{SS}}$ \\
& ${ }^{* *} .20_{\mathrm{GO}}$ & & & & & ${ }^{*} .15 \mathrm{PF}$ & ${ }^{* *} .21_{\mathrm{WS}}$ \\
$F_{(\mathrm{JD}-\mathrm{R})}$ & 7.90 & 21.13 & 2.03 & 3.70 & 4.25 & 10.66 & 14.36 \\
Sig. $F_{(\mathrm{JD}-\mathrm{R})}$ & $.000^{* * *}$ & $.000^{* * *}$ & $.027^{*}$ & $.000^{* * *}$ & $.000^{* * *}$ & $.000^{* * *}$ & $.000^{* * *}$
\end{tabular}

Note: * $p<.05 ;{ }^{* \star} p<.01$; JS=job satisfaction; $\mathrm{AC}=$ affective commitment; $\mathrm{CC}=$ continuance commitment; CSE=classroom self-efficacy; LSE=leadership self-efficacy; RSE=relationship self-efficacy; JD-R=job demands and resources; $\mathrm{ED}=$ =motional demands; $\mathrm{PF}=$ performance feedback; $\mathrm{GO}=$ growth opportunities; $S \mathrm{~S}=$ superordinate support; WS=workmate support. 


\section{DISCUSSION}

Teacher identity has received a great deal of recent attention in both theoretical and empirical literatures. However, a comprehensive measure is still needed. The present study therefore set out to validate a newly constructed instrument the TII - measuring teacher identity through three indicators, namely, teacher self-efficacy, organizational commitment, and job satisfaction.

Most importantly, the TII has justified its conceptualization through three studies using multiple methods. Study 1 focused on item selection and preliminary factorial exploration. Interestingly, we identified seven instead of six factors pertaining to the aforementioned three indicators. The discovery of a new factor confirmed the claim of the importance of leadership self-efficacy and relationship self-efficacy in understanding teacher self-efficacy. Study 2 further calibrated and cross-validated the generated factor structure. Redundant and problematic items were trimmed off through an EFA, and the TII was able to provide factorial confirmation that sufficed to capture perceptions of teacher identity. This time the seven factors totaling 34 items were finalized. Study 3 tested the utility of the TII by exploring its association with the JDRI. Findings were consistent with the theoretical postulate of the JD-RI. Empirically, these findings ascertained what had been reported in prior studies examining constructs similar or connected to teacher identity, such as work engagement, occupational commitment, and teachers' well-being in both western (e.g., Simbula, Panari, Guglielmi, \& Fraccaroli, 2012) and Chinese contexts (e.g., Yang, 2008). The TII was thus proved to be compatible with existing instruments measuring similar constructs or individual components of the three indicators. Our study also supported the viability of TII as a useful tool to assess teacher identity in conjunction with other established instruments like the JD-RI.

As noted earlier, none of the prior instruments of teacher identity has been replicated. Even so, most of these instruments reported instable and moderately satisfactory internal consistency (a: .50 .80) (e.g., Chong, Low, \& Goh, 2011). Differently, the TII in our study was robust to independent replication and cross-replication among multiple populations (two samples from prospective teachers and one from early career teachers). Across these samples, the TII demonstrated better alpha reliabilities ranging from .70 to .92 (see Table 1). More importantly, this internal consistency between items and within factors was corroborated by the employment of the CR and the AVE (Hair et al., 2010). This ensures that the test results in our study did not capitalize on chance such that the TII was internally stable and repeatedly reliable.

Finally, the TII has also proved to be practical in administration. A look at the battery of inventories the TII builds on tells us that there are over 30 items in each original scale, for example, 36 items for measuring organizational commitment (Meyer et al., 1993) and 33 for teacher self-efficacy (Friedman \& Kass, 2002). This makes the plain puttogether of 100 -plus items enormously impractical. However, the finalized 34 -item TII is more than $60 \%$ shorter in length while tapping largely the same constructs and content. Administration time for the TII was thus reduced to a great extent, so would be the attrition rate of participants.

\section{IMPLICATIONS AND LIMITATIONS}

The TII has provided evidence for a new theoretical conjecture of teacher identity, the three-indicator framework. Among the multiple stake holders in education, teachers have been long held secondary to students or parents, thus inadequate concern is attached to the integrity and identity of teachers (Cohen \& Scheer, 2003). Fortunately, teachers have been recently attended to as so important a stakeholder that the issue of teacher identity has been put at the heart of discussion (Lutovac \& Kaasila, 2011). Canrinus et al's (2012) conceptualization thus provides a comprehensive lens to understand teacher identity. Our study has proved that this conceptualization is applicable in varying populations. Also, the TII has proved to be a reliable assessment tool for this conceptualization.

We strongly recommend that independent examinations of the TII be executed for cross-cultural validation. Since the TII was basically adapted to the Chinese context from English inventories, what we await is just independent replication in other cultural contexts. We have to caution that differences in languages might offset the practicability of the TII to a certain extent. We still need to be very careful about the possible presence of moderating or mediating variables in the relationship of teacher identity and other variables, perceived work environment, for example. Table 4 shows that the relationship between continuance commitment (CC) and emotional demands might be moderated or mediated by some unknown variables. These confounders might have changed the directionality of correlation.

However, some limitations to the present study should be addressed in future research. First, the level of motivation is not measured. It is hoped that a test-retest method can be taken among the same sample in future studies to assess changes in the motivation level. This could in the meantime yield evidence for test-rest reliability of the TII. Second, all the data in our study were collected through a single method - self-report questionnaire. This might cause inflated estimates of associations between constructs (Podsakoff, MacKenzie, Lee, \& Podsakoff, 2003). Hopefully, the TII could be validated against the data collected using other methods, such as pupils' ratings for their teachers. Third, female participants predominated in the samples of our study. This might be largely due to the characteristics of participants recruited for teacher education. The generalizability of the findings from our study, however, might be restricted.

To conclude, we finalized and validated a 34-item inventory to measure teacher identity in three independent samples. Theoretical and empirical evidence were obtained for a three-indicator structure of teacher identity proposed by Canrinus et al. (2012). There are good reasons that, as discussed earlier, proper use of the TIl as a tool could make it easier for educational policy-makers and teachers themselves to capture the extremely broad and complicated issue of teacher identity. However, results from our study are preliminary and need further independent replications. Some scales (e.g., job satisfaction) and item contents still need further improvement. 


\section{ACKNOWLEDGMENT}

This work was supported by "the Fundamental Research Funds for the Central Universities" (SWU1509457).

\section{REFERENCES}

[1] Akkerman, F. S., \& Meijer, C. P. 2011. A dialogical approach to conceptualizing teacher identity. Teaching and Teacher Education, 27(2), 308-319. doi: DOI 10.1016/j.tate.2010.08.013

[2] Allinder, R. 1994. The relationship between efficacy and the instructional practices of special education teachers and consultants. Teacher Education and Special Education, 17, 86-195.

[3] Bakker, A. B., ten Brummelhuis, L. L., Prins, J. T., \& der Heijden, F. M. M. A. v. 2011. Applying the job demandsresources model to the work-home interface: A study among medical residents and their partners. Journal of Vocational Behavior, 79(1), 170-180. doi: http://dx.doi.org/10.1016/j.jvb.2010.12.004

[4] Bangs, J., \& Frost, D. 2012. Teacher self-efficacy, voice and leadership: Towards a policy framework for education international. University of Cambridge Faculty of Education: Education International Research Institute.

[5] Beijaard, D. 1995. Teachers' prior experiences and actual perceptions of professional identity. Teachers and Teaching, 1(2), 281-294. doi: 10.1080/1354060950010209

[6] Beijaard, D., Verloop, N., \& Vermunt, J. D. 2000. Teachers' perceptions of professional identity: An exploratory study from a personal knowledge perspective. Teaching and Teacher Education, 16(7), 749-764. doi: $10.1016 / \mathrm{s} 0742-051 \times(00) 00023-8$

[7] Brien, M., Hass, C., \& Savoie, A. 2012. Psychological health as a mediator between need satisfaction at work and teachers' self-perceptions of performance. Canadian Journal of Behavioural Science/Revue Canadienne Des Sciences Du Comportement, 44(4), 288-299.

[8] Browne, M. W. 2000. Cross-validation methods. Journal of Mathematical Psychology, 44(1), 108-132. doi: http://dx.doi.org/10.1006/jmps.1999.1279

[9] Browne, M. W., \& Cudeck, R. 1993. Alternative ways of assessing model fit. In K. A. Bollen \& J. S. Long (Eds.), Testing structural equation models (pp. 136-162). Newbury Park, CA: Sage.

[10] Bryrne, B. M. 2010. Structural equation modeling with AMOS: Basic concepts, applications and programming (2nd ed.). New York: Routledge, Taylor \& Francis Group.

[11] Burn, K. 2007. Professional knowledge and identity in a contested discipline: Challenges for student teachers and teacher educators. Oxford Review of Education, 33(4), 445-467. doi: Doi 10.1080/03054980701450886

[12] Canrinus, E. T., Helms-Lorenz, M., Beijaard, D., Buitink, J., \& Hofman, A. 2012. Self-efficacy, job satisfaction, motivation and commitment: Exploring the relationships between indicators of teachers' professional identity. European Journal of Psychology of Education, 27(1), 115-132. doi: 10.1007/s10212-011-0069-2

[13] Cheung, H. Y. 2008. Measuring the professional identity of Hong Kong in-service teachers. Journal of In-Service Education, 34(3), 375-390.

[14] Chong, S., Low, E. L., \& Goh, K. C. 2011. Developing student teachers' professional identities: An exploratory study. International Education Studies, 4(1), 30-38.

[15] Cohen, R. M., \& Scheer, S. 2003. Teacher-centered schools: Reimagining education reform in the twenty-first century. Lanham, Maryland, and Oxford: The Scarecrow Press, Inc.

[16] Coldron, J., \& Smith, R. 1999. Active location in teachers' construction of their professional identities. Journal of Curriculum Studies, 31(6), 711-726. doi: 10.1080/002202799182954

[17] Conley, S., \& You, S. 2009. Teacher role stress, satisfaction, commitment, and intentions to leave: A structural model. Pshychological Reports, 105(3), 771-786.

[18] Day, C. 2002. School reform and transitions in teacher professionalism and identity. International Journal of Educational Research, 37(8), 677-692. doi: http://dx.doi.org/10.1016/S0883-0355(03)00065-X

[19] Day, C. 2011. Uncertain professional identities: Managing the emotional contexts of teaching. In C. Day \& J. C.K. Lee (Eds.), New understandings of teacher's work: Emotions and educational change (pp. 45-64). Springer Dordrecht Heidelberg London New York: Springer.

[20] Day, C., \& Gu, Q. 2010. The new lives of teachers (1st ed.). London; New York: Routledge.

[21] Day, C., Kington, A., Stobart, G., \& Sammons, P. 2006. The personal and professional selves of teachers: Stable and unstable identities. British Educational Research Journal, 32(4), 601-616. doi: 10.1080/01411920600775316 
[22] Day, C., Sammons, P., Stobart, G., Kington, A., \& Gu, Q. 2007. Teachers matter: Connecting work, lives and effectiveness. Maidenhead: McGraw-Hill/Open University Press.

[23] Demerouti, E., Bakker, A. B., Nachreiner, F., \& Schaufeli, W. B. 2001. The Job Demands-Resources model of burnout. Journal of Applied Psychology, 86, 499-512.

[24] Dworet, D. 1996. Teachers' identities: Overview. In M. Kompf, W. R. Bond, D. Dworet \& R. T. Boak (Eds.), Changing Research and Practice: Teachers' Professionalism, Identities and Knowledge (pp. 67-77). London: Palmer Press.

[25] Ezer, H., Gilat, I., \& Sagee, R. 2010. Perception of teacher education and professional identity among novice teachers. European Journal of Teacher Education, 33(4), 391-404.

[26] Ferketich, S. 1991) Focus on psychometrics: Aspects of item analysis. Research in Nursing and Health, 14, 165168.

[27] Field, A. 2000. Discovering Statistics using SPSS for Windows. London-Thousand Oaks-New Delhi: Sage Publications.

[28] Findlay, K. 2006. Context and learning factors in the development of teacher identity: A case study of newly qualified teachers during their education year. Journal of In-Service Education, 32(4), 511-532.

[29] Flores, B. B., Clark, E. R., Guerra, N. S., Casebeer, C. M., Sánchez, S. V., \& Mayall, H. J. 2010. Measuring the psychosocial characteristics of teacher candidates through the Academic Self-identity: Self-observation Yearly (ASI SOY) Inventory. Hispanic Journal of Behavioral Sciences, 32(1), 136-163. doi: 10.1177/0739986309353029

[30] Fornell, C., \& Larcker, D. F. 1981. Evaluating structural equation models with unobservable variables and measurement error. Journal of Marketing Research, 18(1), 39-50. doi: 10.2307/3151312

[31] Friedman, I. A., \& Kass, E. 2002. Teacher self-efficacy: A classroom-organization conceptualization. Teaching and Teacher Education, 18(6), 675-686.

[32] George, L., \& Sabapathy, T. 2011. Work motivation of teachers: Relationship with organizational commitment/La motivation au travail des enseignants: la relation avec l'engagement organisational. Canadian Social Science, 7(1), 90-99.

[33] Giacometti, K. S. M. 2005. Factors affecting job satisfaction and retention of beginning teachers. Doctor of Education, Virginia Polytechnic Institute and State University.

[34] Goodlad, J. I. 1984. A place called school. New York, NY: McGraw-Hill.

[35] Hair, J. F., Black, W. C., Babin, B. J., \& Anderson, R. E. (Eds.). 2010. Multivariate data analysis (7th ed.). Upper Saddle River, NJ: Prentice Hall.

[36] Harkness, J. A., \& Schoua-Glusberg, A. S. 1998. Questionnaires in translation. In J. A. Harkness (Ed.), Crosscultural survey equivalence (Vol. ZUMA-Nachrichten Spezial, 3, pp. 87-126). Mannheim, Germany: ZUMA.

[37] Helms-Lorenz, M., Slof, B., Vermue, C. E., \& Canrinus, E. T. 2011. Beginning teachers' self-efficacy and stress and the supposed effects of induction arrangements. Educational Studies, 38(2), 189-207. doi: 10.1080/03055698.2011.598679

[38] Hong, J. Y. 2010. Pre-service and beginning teachers' professional identity and its relation to dropping out of the profession. Teaching and Teacher Education, 26(8), 1530-1543. doi: 10.1016/j.tate.2010.06.003

[39] Hoppock, R. 1935. Job satisfaction. New York: Harper and Brothers.

[40] Klassen, R. M., Wilson, E., Siu, A. Y., Hannok, W., Wong, M., Wongsri, N., . . Jansem, A. 2012. Preservice teachers' work stress, self-efficacy, and occupational commitment in four countries. European Journal of Psychology of Education, 1-21. doi: 10.1007/s10212-012-0166-X

[41] Kremer, L., \& Hofman, J. E. 1985. Teachers' professional identity and burn-out. Research in Education, 34, 8995.

[42] Lin, H., \& Hwang, Y. 2014. Do feelings matter? The effects of intrinsic benefits on individuals' commitment toward knowledge systems. Computers in Human Behavior, 30, 191-198. doi: http://dx.doi.org/10.1016/j.chb.2013.07.056

[43] Lorente Prieto, L., Salanova Soria, M., Martínez Martínez, I., \& Schaufeli, W. 2008. Extension of the Job Demands-Resources model in the prediction of burnout and engagement among teachers over time. Psicothema, 20(3), 354-360.

[44] Lutovac, S., \& Kaasila, R. 2011. Beginning a pre-service teacher's mathematical identity work through narrative rehabilitation and bibliotherapy. Teaching in Higher Education, 16(2), 225-236. doi: exploring the nature of becoming a primary10.1080/13562517.2010.515025 
[45] Mclnerney, D. M., Ganotice, F. A., King, R. B., Morin, A. J. S., \& Marsh, H. W. 2014. Teachers' commitment and psychological well-being: implications of self-beliefs for teaching in Hong Kong. Educational Psychology, 1-20. doi: 10.1080/01443410.2014.895801

[46] Meyer, J. P., \& Allen, N. J. 1991. A three-component conceptualization of organizational commitment. Human Resource Management Review, 1(1), 61-89. doi: http://dx.doi.org/10.1016/1053-4822(91)90011-Z

[47] Meyer, J. P., Allen, N. J., \& Smith, C. A. 1993. Commitment to organizations and occupations: Extension and test of a three-component conceptualization. Journal of Applied Psychology, 78(4), 538-551. doi: 10.1037/00219010.78.4.538

[48] Nunnally, J. C., \& Bernstern, I. H. 1994. Psychometric theory. New York, NY: McGraw.

[49] Pillen, M., Beijaard, D., \& den Brok, P. 2013. Professional identity tensions of beginning teachers. Teachers and Teaching, 19(6), 660-678. doi: 10.1080/13540602.2013.827455

[50] Podsakoff, P. M., MacKenzie, S. B., Lee, J., \& Podsakoff, N. P. 2003. Common method biases in behavioral research: A critical review of teh literature and recommended remedies. Journal of Applied Psychology, 88, 879903.

[51] Raubenheimer, J. 2004. An item selection procedure to maximise scale reliability and validity. 59-64SA Journal of Industrial Psychology, 30(4).

[52] Robinson, M., \& McMillan, W. 2006. Who teaches the teachers? Identity, discourse and policy in teacher education. Teaching and Teacher Education, 22(3), 327-336. doi: DOI 10.1016/j.tate.2005.11.003

[53] Secolsky, C. 1987. On the direct measurement of face validity. Journal of Educational Measurement, 24(1), 8283.

[54] Simbula, S., Panari, C., Guglielmi, D., \& Fraccaroli, F. 2012. Teachers' well-being and effectiveness: The role of the interplay between job demands and job resources. Procedia - Social and Behavioral Sciences, 69(0), 729738. doi: http://dx.doi.org/10.1016/j.sbspro.2012.11.467

[55] Stenhouse, L. 1975. An introduct ion to curriculum research and development. London: Heinemann.

[56] Thomason, A. C., \& La Paro, K. M. 2013. Teachers' commitment to the field and teacher-child interactions in center-based child care for toddlers and three-year-olds. Early Childhood Education Journal, 41(3), $227-234$.

[57] Van Dick, R. 2004. My job is my castle: Identification in organizational context. In C. L. Cooper \& I. T. Robertson (Eds.), International Review of Industrial and Organizational Psychology (Vol. 19, pp. 171-203). Chichester, UK.: John Wiley \& Sons, Ltd.

[58] Weiss, D. J., Dawis, R. V., England, G. W., \& Lofquist, L. H. 1967. Manual for the Minnesota satisfaction questionnaire. Minnesota studies in vocational rehabilitation: XXII. Minneapolis, MN: University of Minnesota.

[59] Yang, X.-g. 2008. An empirical study on work engagement of secondary school teachers in China. Doctor of Philosophy, Southwest University.

[60] Yucel, I., \& Bektas, C. 2012. Job satisfaction, organizational commitment and demographic characteristics among teachers in turkey: Younger is better? Procedia - Social and Behavioral Sciences, 46(0), 1598-1608. doi: http://dx.doi.org/10.1016/i.sbspro.2012.05.346

[61] Zehm, S., \& Kottler, J. A. 1993. On being a teacher: The human dimension. Thousand Oaks, CA: Corwin Press.

[62] Zembylas, M., \& Papanastasiou, E. C. 2005. Modeling teacher empowerment: The role of job satisfaction. . Educational Research and Evaluation, 11(5), 433-459.

[63] Živković, P. 2013. Professional development and teachers professional identity: Self-assessment in republic of Serbia. Journal of Educational \& Instructional Studies in the World, 3(1), 150-158.

\section{Author' biography}

Bing Li (1977-), lecturer in the College of International Studies of Southwest University, China. Major research interests of $\mathrm{Li}$ are teacher professional development, occupational and organizational psychology, and the impact of social environment on learning and teaching, and intellectual styles. E-mail: daniel41777@hotmail.com 